\title{
Cagar Budaya dan Memori Kolektif: Membangun Kesadaran Sejarah Masyarakat Lokal Berbasis Peninggalan Cagar Budaya di Aceh Bagian Timur
}

\author{
(Cultural Heritage and Collective Memory: \\ Building Historical Awareness of Local Communities \\ Based on Cultural Heritage in Eastern Aceh)
}

\author{
Aulia Rahman \\ Mufti Riyani \\ Hanafiah \\ Program Studi Pendidikan Sejarah - Universitas Samudra \\ Jalan Meuranda, Langsa Lama, Kota Langsa \\ Tel.: +62 (641) 426535 \\ Surel: auliarahman1985@unsam.ac.id
}

Diterima: 18 September 2019 Direvisi: 23 Maret 2020 Disetujui: 8 Juni 2020

\begin{abstract}
Abstrak
Wilayah Aceh Bagian Timur melingkupi Kota Langsa, Kabupaten Aceh Timur, dan Kabupaten Aceh Tamiang merupakan wilayah yang sangat kaya peninggalan cagar budaya. Warisan peninggalan tersebut dapat menjadi jembatan untuk menghubungkan memori kolektif masyarakat dan membangun kesadaran sejarah. Penelitian ini bertujuan untuk mengidentifikasi dan menelusuri jejakjejak peninggalan masa lalu di wilayah Pesisir Aceh Bagian Timur dan bagaimana proses membangun kesadaran sejarah dengan memori kolektif. Penelitian ini menggunakan metode sejarah. Sumber data diperoleh dengan melakukan penelitian lapangan ke bangunan cagar budaya di wilayah Aceh bagian Timur. Untuk mendukung sumber tersebut, juga dilakukan studi arsip dan pustaka yang relevan dengan topik yang sedang dikaji. Dari hasil penelitian ini, telah dilakukan identifikasi terhadap peninggalan-peninggalan sejarah dan bangunan cagar budaya yang tersebar di wilayah Aceh Bagian Timur. Peninggalan tersebut istana raja-raja, rumah uleebalang, masjid kuno, dan makam keramat. Dari hasil identifikasi tersebut didapatkan adanya unsur memori kolektif yang ada dalam bangunan cagar budaya pada setiap wilayah di Aceh Bagian Timur, yaitu Kabupaten Aceh Tamiang dengan memori Melayu, Islam dan multikultural; Kota Langsa dengan memori masyarakat multikultur; dan Kabupaten Aceh Timur dengan memori Islam. Memori tersebut kemudian digunakan untuk membangun kesadaran sejarah masyarakat Aceh Timur dengan mengaitkan antara ingatan masyarakat, budaya masyarakat, dan kelompok masyarakatnya. Dengan demikian, bangunan cagar budaya bukan sekadar bangunan tanpa makna. Bangunan tersebut merefleksikan kondisi sosial masyarakat di masa lalu dan menjadi potret kehidupan manusia pada masa tersebut.
\end{abstract}

Kata kunci: cagar budaya Aceh, kesadaran sejarah, memori kolektif

\footnotetext{
Abstract

The Eastern Aceh region encompasses Langsa, East Aceh Regency, and Aceh Tamiang Regency, which are rich in historical heritage. The legacy can be a bridge to connect the community's collective memory and build historical awareness. This study aims to identify and trace past relics in the Eastern 12
}

Open acces under CC BY-SA license Creative Commons Attribution-Share Alike 4.0 International License 
Aceh Coastal Region as well as how historical awareness is generated with collective memory. The Eastern Aceh region encompasses Langsa, East Aceh Regency and Aceh Tamiang Regency, which are rich in historical heritage. Thus, its legacy is expected to connect the community's collective memory and build historical awareness. To achieve the objective of this study, qualitative method is used together with historical approach. Data sources are collected through field research in all cultural heritage buildings in the eastern part of Aceh as well as archival and library researches. This study successfully identifies some historical artefacts and cultural heritages in the Eastern Aceh Region, such as the Palace of the Kings, Uleebalang houses, ancient mosques and sacred tombs. Those historical artefacts and cultural heritages in the Eastern Aceh Region have embodied cultural memories triggered by collective memories, namely Aceh Tamiang District with Malay, Islamic and Multicultural memory (harmonious multi-ethnic society); Langsa with multicultural community memory; and East Aceh District with an Islamic memory. All the memories are then used to stimulate public awareness on the history of East Aceh by linking the memories of the community, the culture of the community, and the groups of the community. In short, historical artefacts and cultural heritages in the Eastern Aceh Region reflect the social conditions of the community in the past and becomes a portrait of human life at that time.

Keywords: Aceh cultural heritage, collective memory, historical awareness

\section{PENDAHULUAN}

Sir Charles Firth mengatakan bahwa sejarah merupakan rekaman kehidupan manusia. Dalam rekaman tersebut, selalu terjadi dinamika perubahan dalam bentuk gagasan atau ide maupun material. Sementara itu, John Tosh berpendapat bahwa Sejarah adalah memori kolektif, pengalaman melalui pengembangan suatu rasa identitas sosial manusia dan prospek manusia tersebut di masa yang akan datang (Sanuni 2013). Dengan demikian, peninggalan sejarah yang berbentuk ide-ide dan juga material, merupakan memori kolektif yang berisi pengalaman hidup manusia di masa lalu yang di dalamnya berisi identitas sosial dan menjadi identitas bagi manusia di masa yang akan datang.

Memori atau ingatan adalah kemampuan untuk menyimpan, mempertahankan, dan mengingat kembali kejadian, pengalaman, serta aktivitas yang pernah dilakukan. Memori disimpan dalam tiga sistem penyimpanan, yaitu memori sensori (sensory memory), memori jangka pendek (short term memory), dan memori jangka panjang (long term memory). Sementara itu, memory kolektif atau memori sosial sering kali didasarkan pada mitos atau stereotip sederhana, bukan pada analisis dan evaluasi yang cermat terhadap arsip sejarah.

Meskipun dihargai karena penerapannya pada kejadian terkini, memori kolektif jarang diuji untuk menentukan validitas, keaslian, atau reliabilitasnya. Dengan demikian, memori kolektif akan berubah dan berkelanjutan tunduk pada reinterpretasi agar sesuai dengan kebutuhan masyarakat saat ini. Memori kolektif memberikan kontribusi dalam membentuk identitas diri kelompok sosial, mulai dari kelompok sosial yang paling kecil, seperti keluarga, hingga kelompok sosial terbesar, seperti masyarakat dan bangsa. Memori kolektif mencakup cerita tentang masa lalu atau tentang kelompokkelompok masyarakat dan dengan mengabadikan peristiwa dan pengalaman tertentu sebagai bagian dari masa lalu yang sama. Ia mewujudkan nilai, ritual, dan pandangan hidup untuk melangkah ke masa depan. Seperti kebanyakan konstruksi manusia, memori kolektif dapat digunakan untuk tujuan positif dan mendukung kehidupan atau untuk tujuan parokial dan destruktif, tergantung bagaimana penggunaannya. Misal, dalam konflik Aceh di mana pemberontak dalam konflik Aceh untuk memunculkan mitos-mitos yang berkaitan dengan sejarah Aceh yang terus direkonstruksi dan menjadi memori kolektif bagi masyarakat Aceh. 
Setidaknya terdapat 4 hal yang Aspinall sebut sebagai mitos, yang kemudian menjadi parameter bagi rekonstruksi identitas Aceh. Mitos pertama adalah kepercayaan bahwa Aceh merupakan sebuah negara independen yang pernah mencapai masa keemasannya dengan menguasai semenanjung Malaka dan sebagian Sumatera. Mitos kedua adalah perjuangan heroik masyarakat Aceh dalam mempertahankan diri dari penyerangan Belanda. Mitos ketiga yang berkembang, bahwa Aceh merupakan pertahanan terakhir Indonesia yang berhasil membawa kemerdekaan bagi Indonesia. Perlawanan heroik tersebut dicapai setelah sebelumnya Soekarno bertemu dengan Daud Beureueh dan meminta bantuannya beserta rakyat Aceh untuk mempertahankan Indonesia. Daud Beureueh menyanggupinya dengan persyaratan bahwa kepada Aceh akan diberikan izin untuk melaksanakan syariat Islam. Mitos keempat, yaitu ketika Soekarno mengingkari janjinya yang kemudian melahirkan pemberontakan oleh rakyat Aceh (Aspinall 2009:31-34). Sifat memori kolektif adalah menyederhanakan pengalaman manusia dan hanya memilih aspek-aspek tertentu untuk diingat, selain mengabaikan unsur-unsur yang lebih kompleks dan mungkin dianggap suatu pengalaman buruk pada masa lalu (Foote 1990).

Dalam konteks sejarah, wilayah Aceh Bagian Timur, melingkupi Kota Langsa, Kabupaten Aceh Timur, dan Kabupaten Aceh Tamiang, memiliki catatan perjalanan sejarah yang memiliki karakteristik yang berbeda. Wilayah Kabupaten Aceh Timur memiliki karakter peninggalan Islam yang kuat, Langsa memiliki karakter yang multikultural, dan Aceh Tamiang dengan karakter Islam Melayu. Dengan ragam keunikan tersebut, di wilayah Aceh Bagian Timur tersebar peninggalan cagar budaya yang berisi memori kolektif. Bangunan cagar budaya tersebut dapat menjadi memori kolektif masyarakat, terutama untuk menanamkan nilai religius, multikultural, dan toleransi. Terlebih lagi pada saat ini, sejarah dan memori kolektif di Aceh dimaknai dan diaplikasikan secara negatif. Amirul Hadi dari Pusat penelitian dan Pembelajaran Kebudayaan Aceh IAIN Ar-Raniri Banda Aceh menyebutkan bahwa masyarakat Aceh saat ini masih terjebak dalam memori kolektif mengenai kejayaan masa lalu, sehingga bila terus-menerus terjebak dalam memori kolektif tersebut akan selalu mengajak orang untuk melihat tradisi lama, menjadi romantik, bernostalgia dan pesimis. Tentu saja memori kolektif tipe seperti ini perlu dihindari (Hadi 2014).

Selain itu, Aceh sebagai wilayah pascakonflik tentu saja memiliki memori kolektif tentang konflik yang dominan. meskipun tidak berdampak langsung secara sosial, Aceh pada saat ini perlu memori kolektif untuk perdamaian. Tentu hal ini sangat relevan dengan memanfaatkan media bangunan cagar budaya sebagai jembatan untuk menghantarkan kembali memori kolektif masyarakat di wilayah Aceh Bagian Timur bahwasannya mereka adalah masyarakat yang religius dan toleran.

Cagar budaya adalah warisan budaya bersifat kebendaan berupa benda cagar budaya, bangunan cagar budaya, struktur cagar budaya, situs cagar budaya, dan kawasan cagar budaya di darat dan/atau di air yang perlu dilestarikan keberadaannya karena memiliki nilai penting bagi sejarah, ilmu pengetahuan, pendidikan, agama, dan/atau kebudayaan melalui proses penetapan (Undang-Undang Republik Indonesia 2010). Dalam tulisan ini, penekanan cagar budaya digunakan untuk membangun kesadaran sejarah dengan menanamkan nilai-nilai memori kolektif. Hal ini relevan dengan kegiatan revitalisasi cagar budaya, di mana kegiatan pengembangan ditujukan untuk menumbuhkan kembali nilai-nilai penting cagar budaya dengan penyesuaian fungsi ruang baru yang tidak bertentangan dengan prinsip pelestarian dan nilai budaya masyarakat.

Beberapa penelitian tentang cagar budaya dan memori kolektif telah dilakukan oleh peneliti sebelumnya. Wuisang, dkk. dengan tulisan yang berjudul "Eksistensi Bangunan dan Kawasan Bersejarah di Kota Manado dan Peranannya sebagai Urban Heritage." Dalam tulisannya dijelaskan bahwa nilai penting bangunan cagar budaya bagi masyarakat adalah sebagai pengingat masa lalu, memori budaya masyarakat dahulu, agar nilai sejarah tidak hilang, agar generasi muda mengetahui 
sejarah dan menghargainya, sebagai ikon pariwisata kota, dan mengetahui perkembangan kota (Wuisang, Siregar, dan Mastuti 2018:20). Upaya membangun memori memori kolektif dapat dilakukan dengan menumbuhkan kesadaran tentang pentingnya mengangkat peninggalan masa lalu (Wilaela 2018:50). Selain itu, memori kolektif ini juga dapat berfungsi sebagai sebagai salah satu simpul yang memungkinkan keutuhan masyarakat berkat adanya identitas yang sama (Rostiyati 2019). Dalam konteks memori kolektif, bangunan cagar budaya memiliki nilai historis dan bisa menampilkan sebuah citra visual dari suatu tempat atau kawasan (Salsabila dan Kusuma 2019). Hal ini kemudian yang menjadikan bangunan cagar budaya, yang memiliki citra visual, menjadi jembatan dalam mengantarkan memori kolektif masyarakat.

Berdasarkan kondisi tersebut, diperlukan suatu kajian terhadap untuk mengembalikan memori kolektif masyarakat melalui peninggalan bangunan cagar budaya untuk membangun kesadaran sejarah pada masyarakat lokal dengan mengeksplorasi nilai-nilai sejarah yang tersembunyi dari bangunan cagar budaya. Hasil penulisan ini diharapkan dapat memperkuat identitas masyarakat di wilayah Pesisir Aceh Bagian timur dan dijadikan alternatif dalam pengajaran sejarah serta dikembangkan untuk kepentingan-kepentingan konservasi kesejarahan dan pembangunan identitas social masyarakat.

\section{METODE}

Penelitian ini menggunakan metode sejarah. Sumber data diperoleh dengan melakukan penelitian lapangan ke bangunan cagar budaya di wilayah Aceh Bagian Timur. Penelitian lapangan dilakukan pada bulan Februari hingga Mei 2019, dengan mengidentifikasi bangunan cagar budaya di wilayah Aceh Bagian Timur sesuai dengan karakteristik memori kolektif wilayah. Sebagai data pelengkap, juga dilakukan studi arsip dan pustaka. Selain itu, informasi terkait dengan bangunan cagar budaya di dapatkan dari instansi pemerintah di Kabupaten Aceh Timur, Aceh Tamiang, dan Kota Langsa.

Data yang didapatkan dalam penelitian lapangan antara lain bangunan-bangunan cagar budaya yang memiliki peranan penting dalam perkembangan wilayah dan masyarakat. Selain itu, dalam studi arsip dan pustaka, didapatkan dokumen laporan kolonial terkait perkembangan dan situasi social-politikkeamanan di wilayah Aceh Bagian Timur. Setelah data dikumpulkan, data kemudian dianalisis dan dikaji kembali. Data yang tidak sesuai dengan data lainnya, akan diklarifikasi. Selain itu, penulis juga menggunakan teknik analisis triangulasi untuk mengklarifikasi data dalam tema cagar budaya dan memori kolektif.

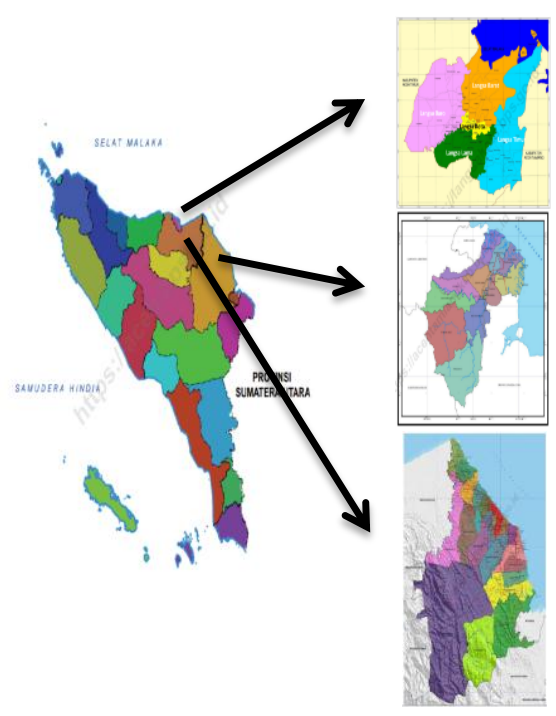

Gambar 1. Lokasi Penelitian 


\section{HASIL DAN PEMBAHASAN}

\section{Identifikasi Cagar Budaya di Wilayah Aceh Bagian Timur}

1. Cagar Budaya di Kabupaten Aceh Tamiang

\subsection{Istana Karang: Istana dan Sejarah Raja-Raja Tamiang}

Istana Karang Tamiang terletak di desa Tanjung Karang, Kecamatan Karang Baru, Kabupaten Aceh Tamiang. (Lestariyati, Yunnarsih, Limbeng 2018). Istana Karang merupakan salah satu kerajaan yang ada di Kabupaten Aceh Tamiang. Kerajaan Karang Tamiang didirikan oleh Raja Proomsyah yang memerintah pada tahun 1558-1590 M. Raja terakhir kerajaan Tamiang adalah Tengku Muhamad Arifin yang berkuasa pada tahun 1925-1945 M. Istana Karang dibangun pada masa pemerintahan Tengku Muhammad Arifin, Raja Karang ketujuh. Beliau adalah anak kandung dari Tengku Achmad Syailani bergelar Paduka Tengku Raja Silang bergelar Kejuruan Karang yang memerintah pada tahun 1902-1925. Sultan Muhammad Arifin meninggal pada tahun 1962 dan dimakamkan di kompleks masjid Istana yang letaknya tidak jauh dari Istana Karang. Kisah tentang raja-raja Karang bisa dipelajari di dalam kompeks makam tersebut, karena di dalam kawasan tersebut menjadi terdapat makam raja dan para kerabat Kerajaan Karang.

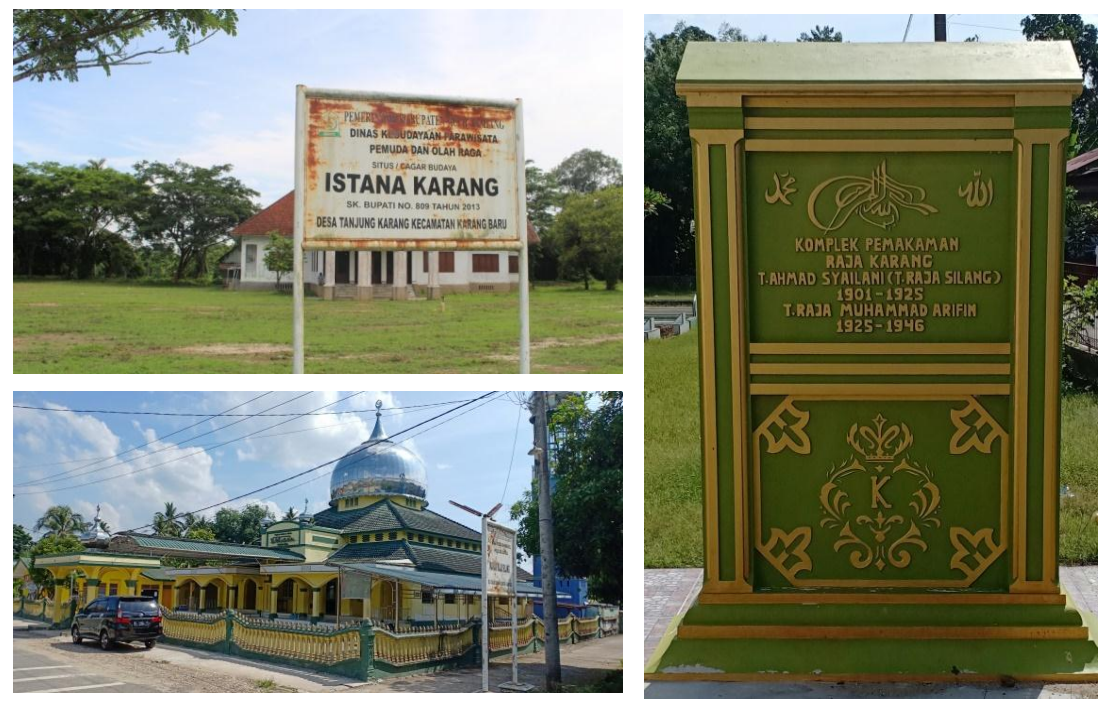

Gambar 2. Istana Karang dan Komplek Pemakaman Raja-Raja Tamiang

(Sumber: dokumentasi pribadi)

\subsection{Istana Benua Raja}

Istana Benua Raja merupakan bangunan peninggalan Kerajaan Benua Raja yang berada di Kabupaten Aceh Tamiang, tepatnya di Desa Benua Raja, Kecamatan Rantau. Istana Benua Raja bergaya arsitektur Eropa, dan didirikan pada masa pemerintahan Sultan Badelisah yang bergelar Tengku Raja Sulung tahun 1928. Tengku Raja Sulung merupakan raja terakhir di Kerajaan Benua Raja. Kerajaan ini adalah salah satu Kerajaan Islam tertua yang ada di Aceh setelah Kesultanan Perlak. Dalam sejarahnya Kesultanan Benua Tamiang ini didirikan pada masa sultan pertama Tuanku Sultan Muda Seudia yang memerintah pada tahun 1330-1352.

Tengku Raja Sulung meninggal akibat dibunuh di wilayah Aceh Utara dan dimakamkan di Bukit Tempurung, Kabupaten Aceh Tamiang (Lestariyati, Yunnarsih, dan Limbeng 2018). Kondisi Istana Benua Raja pada saat ini masih terawat dengan baik, dan hingga kini dihuni oleh ahli waris. Istana ini juga menjadi situs budaya/cagar budaya, tetapi pengelolaannya tetap di tangan ahli waris, bukan oleh pihak pemerintah. 


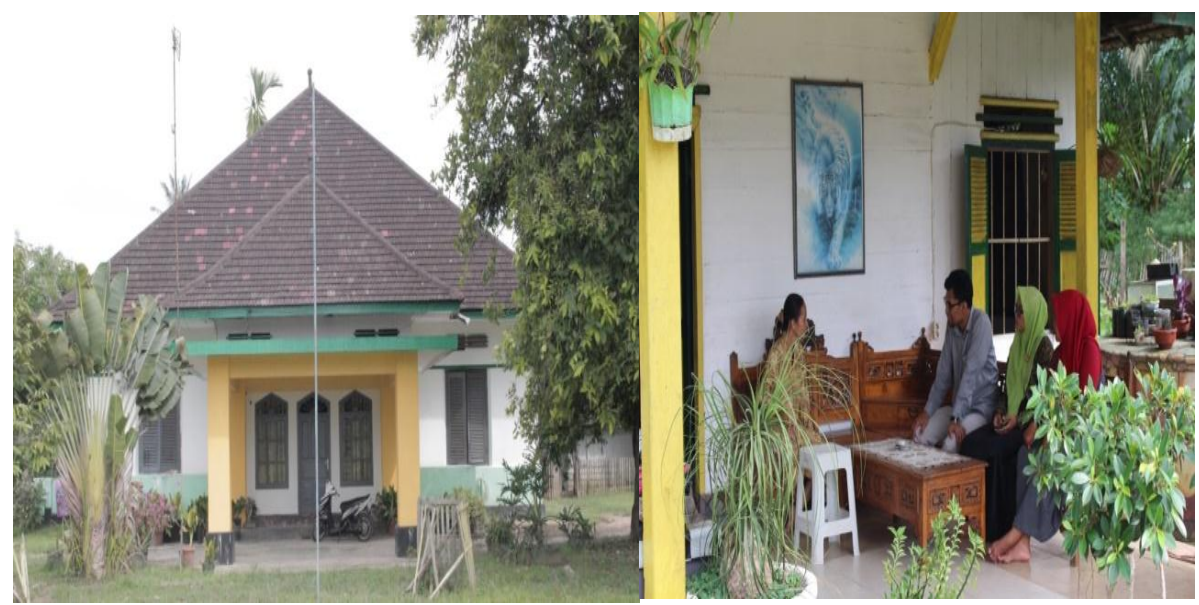

Gambar 3. Istana Benua Raja

(Sumber: dokumentasi pribadi)

\subsection{Istana Seruway}

Istana Seruway memilliki karakter yang berbeda di bandingkan dengan Istana Karang dan Istana Benua Raja. Istana Seruwai memiliki pengaruh melayu Deli yang sangat kuat. Kerajaan Seruway didirikan pada sekitar tahun 1887 oleh Tengku Absah, sedangkan yang duduk di singasana raja adalah Tengku Abdul Majid. Setelah beliau meninggal dunia, posisi itu digantikan oleh anak tunggalnya, yaitu Tengku Zainal Abidin. Tengku Zainal Abidin adalah Raja di Kerajaan Seruway yang terakhir.

Istana Seruway terletak di desa Pekan Seruway, Kecamatan Seruway. Istana ini dibangun pada masa pemerintahan Tengku Zainal Abidin dengan gelar Sultan Muda Indra Kesuma III tahun 1928-1945. Tengku Zainal Abidin merupakan putra dari Tengku Raja Abdul Majid yang diberi gelar Raja Itam (Sultan Muda Indra Kesuma II) yang memerintah pada tahun 1902-1917.
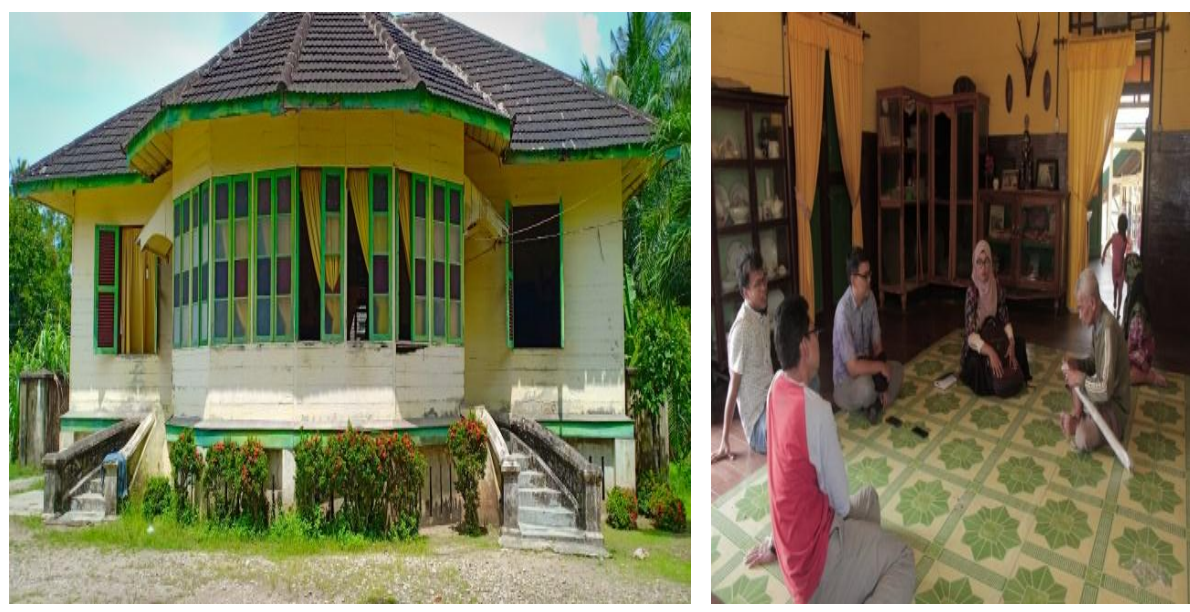

Gambar 4. Istana Seruway

(Sumber: dokumentasi pribadi)

Bangunan Istana sampai saat sekarang ini masih asli, di antaranya lantai, dinding, dan atap masih asli terbuat dari kayu merbau yang diakui ketahanannya lebih dari 120 tahun. Dalam bangunan tersebut 
terdapat 4 kamar dari berbagai sisi bangunan. Sampai sekarang Istana tersebut dihuni oleh keturunan-keturunannya Tengku Zainal Abidin (Lestariyati, Yunnarsih, dan Limbeng 2018).

Istana Seruway secara keseluruhan berarsitektur Melayu (Koestoro et al. 2009). Ciri-ciri identitas arsitektur Melayu tersebut dapat dilihat pada bagaimana penggunaan kayu keras sebagai bahan dasar bangunan, berbentuk rumah panggung, dan memiliki konstruksi bangunan yang menonjol di bagian depan berbentuk persegi lima. Hampir semua bahan bangunannya terbuat dari kayu yang didatangkan dari Penang. Kesemuanya berbahan dasar kayu, kecuali pada atap genteng yang berbahan dasar tanah liat. Umpak penyangga bangunan panggung terbuat dari beton cor, dan tangga masuk yang terbuat dari bata dan semen. Kemudian terdapat anak tangga sejumlah 6 buah yang harus dinaiki untuk masuk ke Istana Seruway yang terdapat di sisi kanan dan kiri

\section{Cagar Budaya di Kota Langsa}

\subsection{Peninggalan Uleebalang Langsa}

Jika di Kabupaten Aceh Tamiang terdapat sejarah Raja-Raja Tamiang, di Langsa juga terdapat kisah Uleebalang. Uleebalang merupakan pemimpin wilayah tradisional. Sejarah ke-uleebalang-an di Langsa tidak terlepas dari sejarah Kesultanan Aceh Darussalam.

Wilayah Aceh Bagian Timur dalam konteks politik-ekonomi di Kesultanan Aceh Darussalam sebenarnya bukan merupakan wilayah yang dapat diandalkan sebelum abad ke-19. Wilayah ini dapat dikatakan wilayah yang sepi dari aktivitas penduduk dan tidak memiliki komoditas unggulan perdagangan. Kondisi seperti ini membuat wilayah Aceh Bagaian Timur menjadi wilayah yang tidak istimewa dan tidak menarik untuk dikunjungi. Di kawasan ini, yang memiliki peranan adalah Peureulak yang dikunjungi oleh Marcopolo pada abad ke-13. Selanjutnya, terdapat kerajaan di pantai utara Aceh, yaitu kerajaan Pidie dan Pasai yang mampu menarik perhatian pada abad ke-16 karena terus menjadi pusat penghasil lada untuk tujuan ekspor. Komoditas perdagangan ini yang kemudian menjadikan wilayah Kesultanan Aceh muncul menjadi kekuatan besar dalam konteks perdagangan internasional (Göksoy 2011:66). Setelah itulah, perkebunan lada kemudian berkembang hingga wilayah Aceh Bagian Timur (Ismail 1991) dan membuat wilayah ini sangat strategis dalam koteks politik dan ekonomi Kesultanan Aceh Darussalam.

Perkebunan lada membuat wilayah Aceh Bagian Timur mulai berkembang dan memunculkan adanya migrasi penduduk dari luar wilayah untuk menanam lada (membuka kebun lada). Akibatnya, mulailah terbentuknya kenegerian-kenegerian baru yang disebut sebagai kenegerian lada (Ismail 1991). Pertumbuhan kenegerian lada tersebut terus terjadi hingga terjadinya perang Belanda di Aceh pada tahun 1873. Terbentuknya kenegerian-kenegerian baru ini tentu saja membawa angin segar kepada pihak Kesultanan Aceh untuk selanjutnya memungut haknya dari penjualan lada.

Termasuk Langsa, didirikan oleh para pendatang. Langsa didirikan pada paruh terakhir abad ke-18 oleh Menangkabauner (orang Minangkabau) yang bernama Datoe Dajang (KITLV 1901). Dengan demikian, yang menjadi pemimpin lokal pada saat itu adalah Datoe Dajang. Namun dalam perkembangannya, yang menjadi pengganti sebagai pemimpin wilayah adalah anak angkatnya. Saat Belanda datang ke Langsa, yang menjadi pemimpin wilayah (uleebalang) di Kenegerian Langsa pada saat itu adalah Teuku Chik Bentara Blang.

Teuku Chik Bentara Blang menolak kehadiran Belanda. Persinggungan antara uleebalang Langsa dengan pemerintah kolonial memuncak pada pada 18 Mei 1877. Pada tanggal tersebut, Teuku Chik Bentara Blang dipaksa menandatangai korte verklaring (pernyataan) sebagai bentuk pengakuan atas kolonialisme Belanda setelah melalui pertempuran. Atas insiden tersebut, Teuku Chik Bentara Blang 
sebagai pemimpin pemberontakan, ditangkap, dan diasingkan ke Kediri, Jawa Timur berdasarkan surat "Perintah Pengasingan" terhadap Teuku Chik Bentara Blang dari Gubernur Sipil dan Militer Aceh, No. 12 tanggal 28 Oktober 1901 (KITLV 1901).

Setelah Teuku Chik Bentara Blang diasingkan, yang menjadi uleebalang selanjutnya adalah Teuku Chik Muda Lam Kuta yang masih saudara dari Teuku Chik Bentara Blang. Lam Kuta memiliki pendirian yang lebih lunak dan cenderung mau mengikuti aturan yang dibuat oleh pemerintah Belanda (KITLV 1901). Selain itu, tentu saja pengangkatan ini berdasarkan campur tangan pemerintah Kolonial Belanda yang tidak ingin kejadian pemberontakan sebelumnya terulang kembali. Dengan demikian, uleebalang baru pengganti Teuku Chik Bentara Blang dapat bertindak secara kooperatif dan mampu mendukung aktivitas Belanda di kenegerian Langsa.

Teuku Chik Muda Lam Kuta meninggal pada 12 Mei 1904, dan ketika akan memilih pewarisnya terdapat perdebatan. Teuku Chik Muda Lam Kuta memiliki lima anak dan yang tertua bernama Teuku Banta Ahmad. Dari saudara Muda Lamkuta yang lain, yaitu Teuku Oebit lebih mengusulkan Teuku Chik Banta Beureudan untuk menjadi penerusnya. Namun, pendapat ini tanpa disertai alasan yang kuat. Pada akhirnya, yang menjadi uleebalang pengganti Teuku Chik Muda Lam Kuta adalah Teuku Chik Banta Beureudan.

Langsa termasuk salah satu wilayah di Aceh Bagian Timur yang berkembang karena adanya perkebunan lada. Perkembangan kenegerian lada ini tentu saja mendapat pengaruh yang sangat besar dari pemimpin lokalnya, yaitu para uleebalang. Jejak pemimpin lokal tersebut masih dapat dijumpai di kompleks Mesjid Istiqamah yang terletak di Gampong Teungoh, Kecamatan Langsa Lama, Kota Langsa. Masjid ini merupakan masjid yang paling awal dibangun di kota Langsa pada tahun 1901 yang diprakarsai pembangunannya oleh Teuku Chik Banta Beureudan.

Di sebelah masjid terdapat kompleks pemakaman uleebalang yang memiliki keterkaitan erat dengan perkembangan dan pertumbuhan Langsa. Di makam tersebut dimakamkan Teuku Chik Banta Beureudan Bin Teuku Chik Muda Lamkuta (Uleebalang/Zelfbestuurder Van Langsa) yang meninggal pada tahun 1918. Kemudian terdapat makam H. T. Ali Basyah Bin T. Cik Banta Beureudan (lahir di Langsa, 11 Februarai 1911, meninggal di Medan 7 Mei 1988), makam Teuku Ismail Bin Teuku Chik Banta Beureudan (lahir 7 Oktober 1917, meninggal 16 Januari 1988), dan makam Hj. Tjut Sariah (Tjut Maneh) binti Teuku Yusuf (lahir di Idi, 17 Maret 1920, meninggal Medan 5 Oktober 2010). Selain itu, ada juga makam lainnya yang memilliki hubungan kekerabatan dengan nama-nama yang telah terlebih dahulu disebutkan.

Selain itu, jejak keberadaan para uleebalang di Langsa juga dapat ditelusuri dari adanya rumah atau istana yang dimiliki dan dijadikan tempat tinggal oleh para uleebalang. Setidaknya terdapat dua rumah yang merupakan peninggalan penguasa lokal yang dikenal dengan rumah uleebalang. Rumah yang pertama adalah rumah Uleebalang Teuku Alibasyah yang terletak di Gampong Teungoh, Langsa Lama. Menurut prasasti yang terukir di bagian depan rumah, rumah ini dibangun pada tahun 1933.

Jejak uleebalang selanjutnya terletak di sebelah timur kantor DPRD Kota Langsa, terdapat rumah uleebalang yang dikenal dengan nama rumah Nya' Maneh. Nama rumah tersebut diambil dari nama pemiliknya, yaitu $\mathrm{Hj}$. Tjut Sariah atau lebih dikenal dengan sebutan Tjut Maneh, binti Teuku Yusuf, yang makamnya juga terletak di kompleks di sebelah masjid Istiqamah Gampung Teungoh. Tjut Maneh merupakan istri Teuku Ismail bin Teuku Chik Banta Beureudan. 


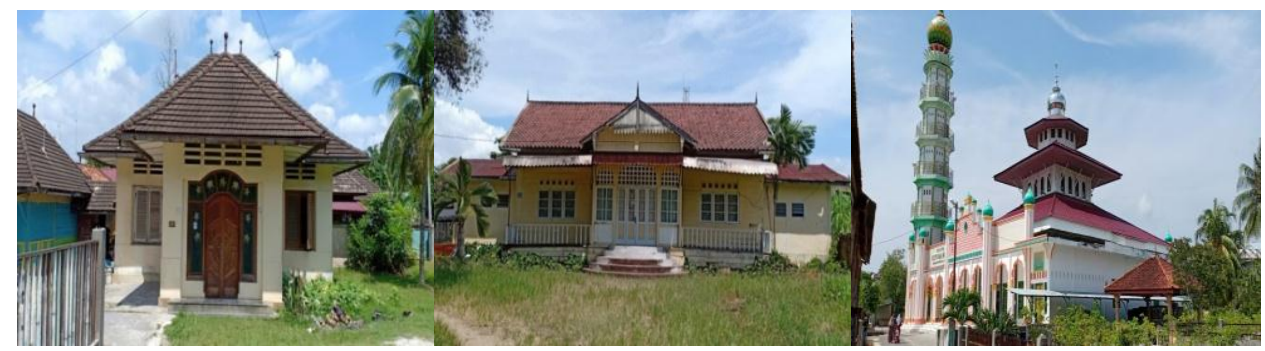

Gambar 5. Rumah Uleebalang, Rumah Cut Nya' Maneh, dan Masjid Istiqamah (Sumber: dokumentasi pribadi)

\section{Cagar Budaya di Kabupaten Aceh Timur}

\subsection{Uleebalang Labuhan dan Perkembangan Julok}

Labuhan merupakan gampong yang sekaligus menjadi pusat permukiman yang berada di sebelah barat wilayah Kuta Binjei, ibukota Kecamatan Julok. Wilayah Labuhan pernah menjadi pusat wilayah pertama sebelum akhirnya berpindah di Kuta Binjei. Hal itu dibuktikan dengan adanya sebuah masjid tua yang didekatnya juga terdapat komplek pemakaman Uleebalang Julok Rayeuk

Di komplek meunasah Desa Labuhan, Kuta Binjai terdapat makam yang menurut penduduk setempat adalah makam uleebalang dan juga orang penting dalam perkembangan wilayah tersebut. Menurut Suriadi, Kasi Sejarah dan Cagar budaya Kabupaten Aceh Timur, komplek makam tersebut adalah adalah makam Uleebalang Kenegerian Julok Rayeuk dan keluarganya. Kawasan ini lebih dikenal dengan Teupin Lada yang merupakan pelabuhan untuk aktivitas bongkar-muat lada dan komoditas pertanian lainnya di Kenegerian Julok Rayeuk pada abad ke-19. Di salah satu makam masih jelas tertulis epitaf dengan bahasa Jawi yang berbunyi "Teuku Raja Hitam Bin Teuku Bentara Cut Lambita. Julok Besar yang telah kembali Ke Rahmatullah pada hari kamis, 7 syawwal 1320 (1902 M)." Oleh masyarakat setempat, makam ini lebih dikenal sebagai makam Teungku Syahid. Teuku Raja Hitam wafat dalam peperangan dengan Belanda dalam expeditie Belanda di wilayah Aceh Bagian Timur.

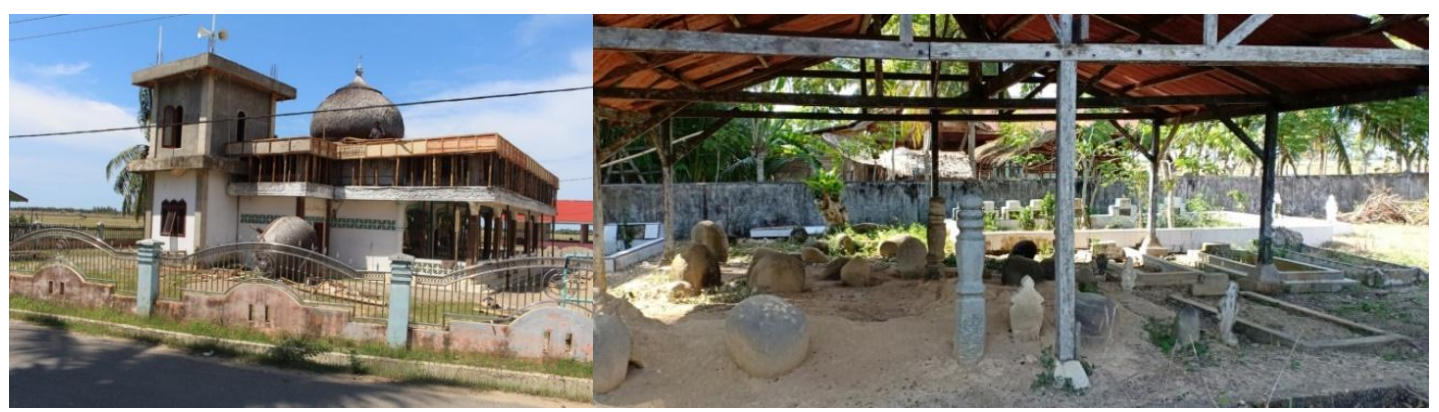

Gambar 6. Masjid Labuhan dan Kompleks Makam Uleebalang

(Sumber: dokumentasi pribadi)

\subsection{Dinamika dan Perkembangan Sejarah di Wilayah Perlak}

Kecamatan Perlak pada saat ini merupakan bagian dari Kabupaten Aceh Timur. Namun pada masa Kolonial Belanda, kenegerian Perlak masuk di bawah onderafdelling Langsa (Stibbe 1918). Batas wilayah Kenegerian Perlak: utara: mulai dari Peudawa (dari Koeala Sembilan di atas Aloe Boeë, Aloeë Oedép ke Boekit Panjang, yang batasnya ditentukan oleh keputusan Gubernur Sipil dan Militer Aceh dan audiensi orang para tetua adat (orang tua) tanggal 27 Juni 1900 Nomor 118/K; timur: di tepi laut; ke selatan: dekat Sungai Bajan; dan ke barat: mulai dari negara-negara Gayo (Gajo), yang batasnya masih belum ditentukan. Selanjutnya, bentang alam Soengoë Raya membentuk kantong di 
daerah tersebut. Soengoë Raya sebelum tunduk di bawah Perlak merupakan sebuah wilayah yang mandiri sejak 1899. Hanya berdasarkan kontrak sebelumnya, Uleebalang dari Soengoë Raya membayar kepada Kenegerian Perlak sejumlah 12 dolar per kojang lada yang diekspor sebagai bentuk pajak atau upeti. Secara politik, Soengoë Raya adalah wilayah yang mandiri (KITLV 1903).

Perlak sebagai sebuah wilayah masyhur sebagai tempat pertama kali masuknya agama Islam di Asia Tenggara pada abad ke-7 (Abdullah 2007:7). Kisah tentang Kerajaan Perlak kemudian dikisahkan oleh Marcopolo yang singgah ke Kerajaan Perlak pada abad ke-13. Marcopolo menceritakan tentang kebesaran Kerajaan Perlak yang juga menjadi pusat ekonomi, dan penduduk Perlak ketika itu telah diislamkan oleh pedagang-pedagang yang diberikan sebutan olehnya kaum Sarasen (Ibrahim et al. 1991:40). Di Pelabuhan Perlak waktu itu banyak berdiam pedagang-pedagang Islam dari berbagai negeri seperti Parsi, Arab, dan India. Dalam perkembangannya, terjadi pernikahan campuran antara para pedagang dengan penduduk lokal. Dari pernikahan tersebut kemudian lahir Said Abdul Aziz. Dengan bantuan dan sokongan para pedagang-asing yang menganut Islam, Said Abdul Aziz berhasil merebut kekuasaan Raja Perlak dan kemudian mendirikan Kesultanan Perlak. Said Abdul Aziz dinobatkan menjadi Sultan Perlak dengan gelar Sultan Alaidin Syah (Ibrahim et al. 1991:41).

Namun setelah itu, keberlanjutan cerita tentang Kerajaan Perlak terputus. Beberapa abad kemudian, tepatnya pada awal abad ke-19, Belanda masuk ke Aceh dan kemudian menguasai secara bertahap dan masuk hingga wilayah pedalaman Aceh, salah satunya adalah Peureulak. Belanda menceritakan tentang asal-usul wilayah Perlak dalam Encyclopedia van Nederland Indie. Pendiri pertama lanskap Peureulak adalah orang Minangkabau yang bernama Datoe Panglima Garang, yang berasal dari Serbödjadi, dan kemudian menetap di wilayah Koeala (Pantai di Perurelak). Di sana ia menikahi seorang wanita dari Djoelo Rajeu (Julok Rayeuk) di mana ia memiliki seorang anak perempuan. Putri Datoe Panglima Garang kemudian menikah dengan Datoe Doelah dari Pasai. Putri Datoe Doelah ini kemudian menikah dengan Datoe Po Kalam, orang Aceh yang berasal dari Indrapuri. Datoe Po Kalam ini menjadi ueleebalang pertama yang disebut di wilayah yang sekarang dikenal sebagai Peureula $( \pm 1775)$ (Stibbe 1918).

Peninggalan sejarah dan cagar budaya yang terdapat di Perlak saat ini adalah adalah makam Sultan Alaidin Said Maulana Abdul Aziz Syah yang diyakini sebagai pendiri kerajaan Islam pertama di Asia Tenggara yang terletak di Bandar Khalifah, Peureulak. Sultan Alaidin Berkuasa pada tahun 840-864, dan meninggal pada tahun $864 \mathrm{M}$.

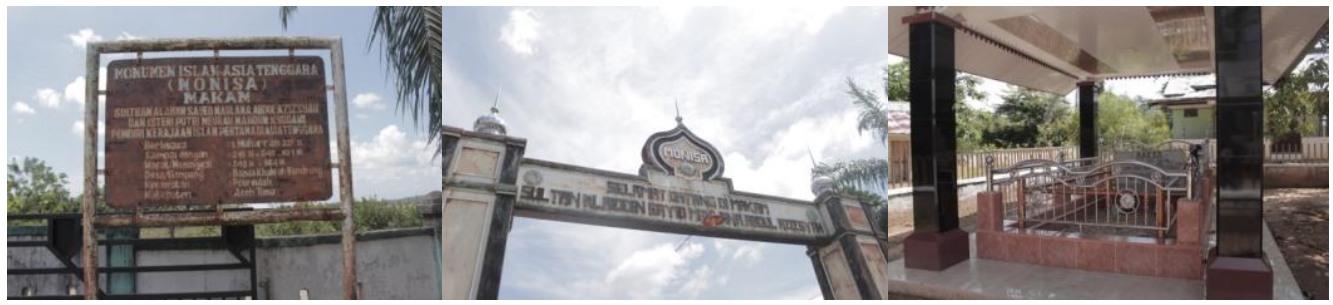

Gambar 7. Makam Sultan Alaidin Said Maulana Abdul Aziz Syah (Sumber: dokumentasi pribadi)

\section{Cagar Budaya, Memori Kolektif, dan Membangun Kesadaran Sejarah}

Pembentukan budaya didapatkan dari pengalaman kolektif yang mengkristal yang di dapatkan melalui proses yang panjang. Pada saat kebudayaan terbentuk, kebudayaan tersebut dapat menjadi jembatan untuk mengakases kembali pengalaman kolektif tersebut. 
Dalam tulisan ini, memori kolektif yang dimaksudkan adalah memori kolektif budaya, yang termanifestasikan dalam bentuk bangunan cagar budaya. Memori budaya memiliki ciri khas terkait dengan jaraknya dengan kehidupan sehari-hari. Selain itu, memori budaya memiliki titik tetapnya; cakrawala tidak berubah seiring berlalunya waktu. Poin-poin tetap ini adalah peristiwa-peristiwa penting di masa lalu, yang ingatannya dipertahankan melalui pembentukan budaya (Assmann 1995:129).

Setelah melakukan penelitian di wilayah Aceh Bagian Timur, terdapat tiga karakter budaya yang didapatkan. Pertama, dalam sejarah Raja-Raja Tamiang yang menjadi fondasi sejarah Kabupaten Aceh Tamiang memiliki keterkaitan yang kuat terhadap sejarah Melayu dan Islam. Unsur Melayu yang paling kuat dapat dilihat dari bangunan Istana Seruway (Lestariyati, Yunnarsih, dan Limbeng 2018a). Kemudian, pengaruh unsur Islam di Kerajaan Tamiang bisa dilihat dari masuknya pengaruh Melayu, masuknya kekuasaan Kerajaan Aceh Darussalam, serta hubungan dengan Kesultanan Turki melalui Kerajaan di Sungai Iyu (Özay 2017). Kedua, di Kota Langsa sangat kuat unsur masyarakat multikultural. Uleebalang sebagai pemimpin lokal mampu mengorganisasi masyarakat Langsa yang hampir semuanya merupakan pendatang dari luar Langsa. Terlebih ketika masuknya kolonial Belanda di Langsa pada tahun 1877, dam mulainya industrialisasi perkebunan di Langsa pada tahun 1907 (Muhajir, Yuliati, dan Rochwulaningsih 2017) membuat arus pekerja perkebunan masuk ke Langsa semakin banyak. Ketiga, Kabupaten Aceh Timur yang memiliki unsur Islam. Situs monumen Islam Asia tenggara dan makam Sultan Alaidin Said Maulana Abdul Aziz Syah yang diyakini sebagai pendiri kerajaan Islam pertama di Asia Tenggara yang terletak di Bandar Khalifah (Perlak), menjadi bukti bahwa dengan adanya situs ini, memori budaya yang terbangun oleh masyarakat adalah memori sejarah Islam.

Dalam membangun kesadaran sejarah berbasiskan bangunan cagar budaya ini, yang perlu diperhatikan adalah kekuatan objektivasi budaya dalam menstabilkan memori budaya dalam situasi tertentu dalam waktu yang lama. Perlu adanya hubungan yang jelas antara ingatan, budaya, dan kelompok.

Pada dasarnya, tidak ada memori yang bisa menjaga masa lalu sepenuhnya. Memori pada masa lalu bisa direkonstruksi dan dimaknai oleh masyarakat pada setiap zaman, karena setiap perubahan memiliki semangat yang berbeda. Sementara itu, bangunan cagar budaya konteks bangunan (materiil) memiliki nilai yang tetap, tidak bergerak dan menyimpan pengetahuan. Dengan memanfaatkan memori budaya, bangunan cagar budaya dapat bekerja dengan merekonstruksi dengan menghubungkannnya dengan pengetahuan serta situasi aktual-kontemporer.

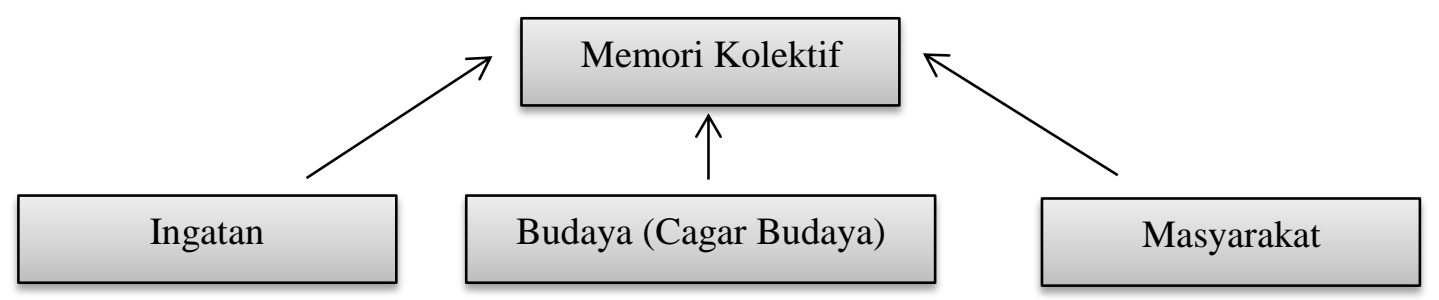

Bagan 1. Proses Pembangun Kesadaran Sejarah dengan Memori Kolektif

Membangun kesadaran sejarah melalui memori kolektif merupakan sebuah aktivitas yang bertumpu pada ingatan sosial. Dalam melakukan aktivitas tersebut selalu menggunakan simbol-simbol yang diciptakan secara sosial (Wattimena 2016). Dalam penelitian ini, simbol yang dimaksudkan adalah bangunan cagar budaya maupun tulisan atau pun gambar-gambar yang tertuang dalam bangunan cagar budaya tersebut. Bangunan cagar budaya tersebut memiliki kenangan dan ingatan di dalamnya. 
Kenangan dan ingatan tersebut merupakan bentukan dari konteks sosial yang ada di masyarakat sekitar.

Wilayah Aceh Bagian Timur memiliki potensi sejarah yang bisa digunakan untuk menjembatani generasi masa sekarang dengan masa lalu untuk menjaga memori kolektif tentang sejarah sebagai identitas, akar, serta rasa hormat terhadap para leluhur. Bangunan cagar budaya yang telah disebutkan di atas merupakan tempat untuk menyimpan berbagai jejak masa lalu. Jejak yang dimaksudkan di sini bukan hanya tentang bangunan-bangunan fisik perkembangan kota, melainkan juga kota sebagai tempat berinteraksi antara manusia pada masa itu. Lebih jauh, peninggalan cagar budaya tersebut juga menyajikan perkembangan fenomena sosial, termasuk aktivitas sehari-hari masyarakat kotanya.

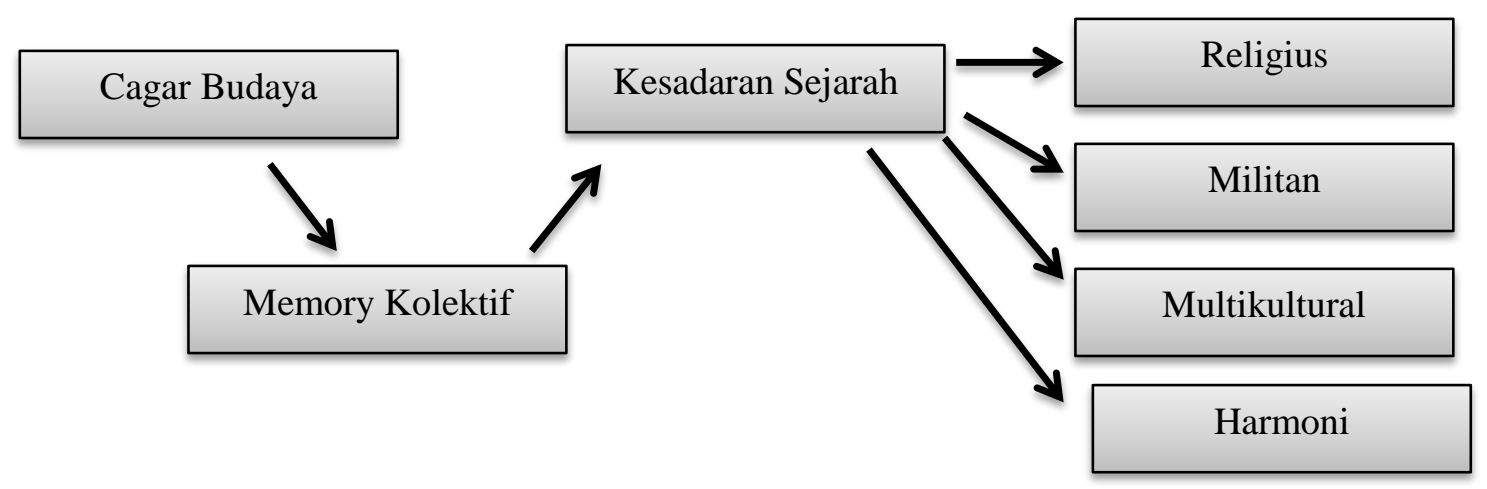

Bagan 2. Hasil Memori Kolektif dan Kesadaran Sejarah

Dengan menjadikan peninggalan cagar budaya yang ditinggalkan untuk menumbuhkan kesadaran sejarah sebagai memori kolektif bersama, masyarakat akan teredukasi dengan nilai-nilai yang diajarkan pada bangunan peninggalan cagar budaya tersebut. Dengan demikian, masyarakat akan lebih mengenal dengan dirinya sendiri, memiliki identitas yang berakar kuat dengan leluhur, dan hal itu digunakan sebagai modal sosial dalam menghadapi perkembangan jaman.

\section{SIMPULAN}

Dari hasil penelitian ini, telah dilakukan identifikasi terhadap peninggalan-peninggalan sejarah dan bangunan cagar budaya yang tersebar di wilayah Aceh Bagian Timur. Peninggalan tersebut adalah Istana raja-raja, rumah uleebalang, masjid kuno, dan makam Kkeramat.

Dari hasil identifikasi tersebut didapatkan adanya unsur memori kolektif berupa memori budaya yang ada dalam bangunan cagar budaya pada setiap wilayah di Aceh Bagian Timur, yaitu Kabupaten Aceh Tamiang dengan memori Melayu, Islam, dan multikultur; Kota Langsa dengan memori masyarakat multikultur; dan Kabupaten Aceh Timur dengan memori Islam. Memori tersebut kemudian digunakan untuk membanguan kesadaran sejarah masyarakat Aceh Timur dengan mengaitkan antara ingatan masyarakat, budaya masyarakat, dan kelompok masyarakatnya.

Dengan demikian, bangunan cagar budaya bukan sekadar bangungan tanpa makna. Bangunan tersebut merefleksikan kondisi sosial masyarakat di masa lalu dan menjadi potret kehidupan manusia pada masa tersebut. Dengan demikian, bangunan peninggaan cagar budaya di wilayah Aceh Bagian Timur ini dapat dijadikan sebagai sarana keberlanjutan identitas dan menumbuhkan kesadaran sejarah masyarakat di wilayah Aceh bagian Timur yang Islami, multikultur, dan harmonis. 


\section{DAFTAR PUSTAKA}

Abdullah, M. Jakfar. 2007. "Diantara Agama dan Budaya: Suatu Analisis tentang Upacara Peusijuek di Nanggroe Aceh Darussalam." Kuala Lumpur: Universiti Sains Malaysia.

Assmann, Jan dan John Czaplicka. 1995. "Collective Memory and Cultural Identity." New German Critique 65.

Aspinall, Edward. 2009. Islam and Nation: Separatist Rebellion in Aceh, Indonesia,. Stanford/Palo Alto: Stanford University Press.

Foote, Kenneth E. 1990. "To Remember and Forget: Archives, Memory, and Culture." American Archivist 53(3):378-92.

Göksoy, İsmail Hakkı. 2011. "Ottoman-Aceh Relations as Documented in Turkish Sources.” In Mapping the Acehnese Past. Brill.

Hadi, Amirul. 2014. "Masyarakat Aceh Masih Terjebak Memori Kolektif Keyayaan Masa Lalu." Harian Pelita.

Ibrahim, Muhammad, M. Arifin, Nasruddin Sulaiman, Rusdi Sufi, Zakaria Ahmad, Hasan Mu'arif Ambary, dan T. Ibrahim Alflan MA. 1991. Sejarah Daerah Propinsi Daerah Istimewa Aceh. Jakarta: Departemen Pendidikan dan Kebudayaan Direktorat Sejarah dan Nilai Tradisional Proyek Inventarisasi dan Dokumentasi Sejarah Nasional.

“Undang-Undang Republik Indonesia Nomor 11 Tahun 2010 tentang Cagar Budaya.” 2010.

Ismail, Muhammad Gade. 1991. Seuneubok Lada, Uleëbalang Dan Kumpeni: Perkembangan Sosial Ekonomi Di Daerah Batas: Aceh Timur, 1840-1942. Leiden: Diss. Rijksuniversiteit te Leiden.

KITLV, Redactie. 1901. "Mede Deelingen Betreffende de Atjehsche Onderhoorigheden." Journal of the Humanities and Social Sciences of Southeast Asia 63(1):138-171.

KITLV, Redactie. 1903. "Mededeeltngen Betreffende Atjehsche Onderhoorigheden." Journal of the Humanities and Social Sciences of Southeast Asia 55(1):363-401.

Koetoro, Lucas Partanda, Andri Restiyadi, Ratna, Indra Afkhar, dan Rita Margaretha Setianingsih. 2009. "Situs dan Objek Arkeologi-Historis Kabupaten Aceh Tamiang, Provinsi Nanggroe Aceh Darussalam.” Berita Penellitian Arkeologi 2. Medan: Balai Arkeologi Sumatera Utara.

Lestariyati, F. Sri, Ratna Yunnarsih, dan Julianus Limbeng. 2018a. Digitalisasi Data Keraton: Istana Seruway Aceh Tamiang. Jakarta: Direktorat Kepercayaan terhadap Tuhan Yang Maha Esa dan Tradisi Direktorat Jenderal Kebudayaan Kementerian Pendidikan dan Kebudayaan.

- 2018b. Digitalsasi Data Keraton: Istana Benua Raja Aceh Tamiang. Jakarta: Direktorat Kepercayaan terhadap Tuhan Yang Maha Esa dan Tradisi Direktorat Jenderal Kebudayaan Kementerian Pendidikan dan Kebudayaan.

. 2018. Digitalisasi Data Keraton: Istana Karang Aceh Tamiang. Jakarta: Direktorat Kepercayaan 
terhadap Tuhan Yang Maha Esa dan Tradisi Direktorat Jenderal Kebudayaan Kementerian Pendidikan dan Kebudayaan.

Muhajir, Ahmad, Dewi Yuliati, dan Yety Rochwulaningsih. 2017. "Industrialisasi dan Eksistensi Kota Langsa Pada Era Kolonial, 1907-1942.” Paramita-Historical Studies Journal 27(1):063-076.

Özay, Mehmet. 2017. "The Attahashi Family: The Genealogy of the Ruler of Sungai Iyu in Aceh.” Insan EF Toplum Dergisi (The Journal of Human E Society) 7(2):23-44.

Rostiyati, Ani. 2019. “Toleransi Keragaman pada Masyarakat Cigugur Kuningan.” Patanjala: Jurnal Penelitian Sejarah dan Budaya 11(1):65.

Salsabila, Levana dan Hanson E. Kusuma. 2019. "Perspektif Apresiatif dan Rekreatif Pada Kawasan Cagar Budaya, Kasus Studi: Kawasan Braga Di Bandung.” Ruas 17(1):32-42.

Sanuni, Anwar. 2013. Pengantar Ilmu Ilmu Sejarah. Cirebon: Syekh Nurjati Press.

Stibbe, S. De Graaf en D. G. 1918. Encyclopaedie van Nederlandsch Indië, Derde Deel. Leiden: 's Gravenhage.

Wattimena, Reza A. 2016. "Mengurai Ingatan Kolektif Bersama Maurice Halbwachs, Jan Assmann, dan Aleida Assmann." Studia Philosophica et Theologica 16(2):164-96.

Wilaela. 2018. "Pemanfaatan Peninggalan Sejarah di Riau Menuju Daerah Ekoeduwisata." Sosial Budaya 15(1):43.

Wuisang, Cynthia E. V., Frits O. P. Siregar, dan Faizah Mastuti. 2018. “SPACE.” Space 5(1). 